\title{
Quantification of Wrist Flexors Strength by Hand-Held Dynamometer with Respect to Grades of Manual Muscle Testing in Young Females
}

\section{Saadia Perwaiz'1, Muhammad Waqar Afzal2 ${ }^{2}$, Ghulam Fatima ${ }^{3}$}

\begin{abstract}
$\frac{\text { Author's Contribution }}{1,4-5 \text { Conception and design, Collection }}$ and assembly of data, ${ }^{2-3}$ Analysis and interpretation of the data, ${ }^{1-2}$ Critical revision of the article for important intellectual content, Statistical expertise 1 Final approval and guarantor of the article.
\end{abstract}

${ }^{1}$ Lecturer, Akhtar Saeed College of Rehabilitation Sciences, AMDC Lahore

${ }^{2}$ Incharge Physiotherapy Clinic/Assistant Professor, University of Lahore Teaching Hospital.

${ }^{3}$ Assistant Professor, Life and Health Department, University of South Asia, Lahore

Article Info.

Received: Sep 25, 2020

Acceptance: June 25, 2021

Conflict of Interest: None

Funding Sources: None

Address of Correspondence

Dr Saadia Perwaiz

Email ld:s_perwaiz@yahoo.com

Cite this article as: Perwaiz S, Afzal MW, Fatima G. Quantification of Wrist

Flexors Strength by Hand-Held Dynamometer with Respect to Grades of Manual Muscle Testing in Young Females. JRCRS. 2021; 9(1). 36-40. DOI: https://dx.doi.org/10.53389/JRCRS.20 $\underline{21090108}$

\section{A B S T R A C T}

Objective: To quantify the strength of dominant and non-dominant wrist flexors with respect to grades of manual muscle testing in young healthy females of different age group.

Methodology: In this cross-sectional study 300 young healthy females in the age of 18-39 years were enlisted. The sampling technique employed was non-probability convenience Sampling. The strength of dominant and non-dominant wrist flexors of young females was quantified through manual muscle testing and hydraulic Hand-Held dynamometer. The strength measured by dynamometer was then evaluated and formulated in accordance with grade 4 and 5 in three different age groups. The SPSS version 25 was used for data analysis and the values were formulated by comparing mean values of the quantitative strengths with respect to grades in respective age group through independent sample ttest.

Results: In dominant side $182(60.70 \%)$ participants had normal muscle strength with quantitative mean as $7.24 \pm 1.71 \mathrm{~kg}$ and range of dynamometrical measures was 3.63$15.65 \mathrm{~kg}$, the muscle strength of $118(39.30 \%)$ participants was in grade 4 with quantitative mean to be $6.55 \pm 1.42 \mathrm{~kg}$ minimum-maximum range of strength was $3.17-11.68 \mathrm{~kg}$;. In nondominant side $183(61.00 \%)$ participants were in grade 5 with dynamometric mean as $7.05 \pm 1.65 \mathrm{~kg}$ and range of variation of muscle strength was $3.17-11.45 \mathrm{~kg} .117(39.00 \%)$ participants were found to have strength of wrist flexors in grade 4 , with dynamometric mean as 6.40+1.44 kilogram and minimum-maximum range varying between $2.95-11.68 \mathrm{~kg}$. Conclusion: The available range of strength measured by dynamometer in dominant and non-dominant wrist flexors of young healthy females showed overlap between grade 4 and 5 revealed by minimum and maximum ranges across both grades. A significant number of normal healthy population had weaker wrist flexors. The dominant side was stronger as compared to non-dominant.

Keywords: Muscle Strength Dynamometer, Muscle strength, Wrist flexors.

\section{Introduction}

Wrist flexion is an important component of functional movements of upper extremity. The functional movements with an emphasis on hygiene activity consumes up to 50 degrees of range of flexion at wrist, ${ }^{1}$ as compared to normal range of motion varying between 84- 98.2 degrees in different populations with varying characteristics. ${ }^{2}$ However, the most common range recommended is $0-90$ degrees. ${ }^{3}$ Wrist flexors play an intricate and compulsive role with combine movements in formulating grip strength and other fine motor movements. In addition to this, wrist flexors along with extensors also play important and diverse role in various movements at elbow joint. ${ }^{2}$ The normal strength of wrist flexors has been discussed in many studies and populations. The common 
tools that are used in clinical practice to measure the strength of wrist flexors are dynamometers and manual muscle testing. Manual muscle testing is the most basic tool which quantifies strength into five grade with subjective approach. The gravity and resistance of the therapist are the main forces based upon which output of the muscle is measured. Its reliability and validity is well established in various studies involving different muscle groups. 4,5 However, the submaximal and maximal resistance in grade 4 and 5 questions the validity of manual muscle testing. ${ }^{6}$

Hand-held dynamometers are well known for their objective approach as they measure the strength in pounds and kilograms and are meant to detect small strength differences which is valuable in the context of measurement of muscle strength as an outcome measure. 7,8 Varied range of strength of wrist flexors is available in context of different populations owing to muscle mass, body mass index and activity level. The main criteria which is usually considered to measure reference values in normal population, considers absence of health ailment to be standardized approach. 9, 10 Does lack of health condition ensures the normal muscle strength, it is an area that is needed to be studied further. There are studies which indicate reduced muscle strength as an overall deterioration in general health condition quite earlier to the appearance of gross ailment. There are a lot of studies that measure strength differences in normal population in different population especially western and Caucasian populations. However, there has been lack of standardized quantification of strength in Asian populations.

In this context this study measures and quantifies the strength of wrist flexors in normal healthy females with respect to grades. The grade five of manual muscle testing is reference standard which defines the normal muscle strength. The measure of dynamometric muscle strength against this standard is used to derive reference value for normal wrist flexors in young females. The purpose of this study is to objectify the subjective approach of manual muscle testing across grade 4 and 5 .

$$
\text { Methodology }
$$

In this study the strength of wrist flexors of 300 young adult females in range of 18- 39 years was measured. It was a cross-sectional study design. The study size was calculated by formula

$$
\begin{aligned}
& \frac{z_{I-\frac{\alpha}{2}}^{2} \operatorname{sn}(1-S n)}{L^{3} \times P_{\text {revalence }}}, \text { here } Z_{I-\frac{\alpha}{2}}^{2}=(1.96)^{2} \\
& \text { Sp. }=89.2, L=6 \text {, Prevalence }=65.4 \% .7)
\end{aligned}, S n=62.9 \text {, }
$$

The population in the age of 18-39 years was divided into 3 age groups (18-19, 20-29, 30-39). The grouping technique was discrete age grouping in which the participants above 19 years of age and less than 20 years were included in age group of 18-19 years. Similar, methodology was adopted for remaining two age groups. The selected age and age groups were based on strength differences with reference to studies of Bohannon and Backman. ${ }^{10,11}$

Young healthy females without any ailment of upper extremity in age group of 18-39 years were selected. Those having any ailment of upper extremity (deformity, or musculoskeletal abnormality), neurologic, musculoskeletal, cardiovascular or any systemic illness were excluded. The sample was collected by nonprobability convenience sampling method. The research was approved by Institutional review board of University Institute of Physical Therapy, University of Lahore. With the consent of the participants the data was collected from Association of Fatima Jinnah old graduate's association and the University of South Asia, Lahore. The strength of wrist flexors of both extremities was evaluated by manual muscle testing and hand held dynamometer. In case of manual muscle testing the subjects were in shortsitting, wrist was neutral, forearm supinated and supported. Two female therapists measured the strength. The therapist applied resistance on the palm of the participant with thumb circling the dorsal surface of hand. The subjects were instructed to flex the wrist while keeping the fingers and thumb relaxed. Depending upon exertion of the participant the strength was categorized as grade 4 (Good) and grade 5 (normal). ${ }^{3}$

For dynamometric measurements the protocol of make test was employed. The subjects were seated with arm stabilized on the table edge, palm in, wrist slightly flexed and fingers relaxed. The therapist held dynamometer against the head of metacarpophalangeal joint while stabilizing the forearm of subject with other hand against the table. Using standard protocol of isometric make test 
two readings were taken, and in case where two readings were inconsistent (difference between both readings was more than 10 percent) mean of three readings were used as reference value. ${ }^{9}$ The SPSS version 25 was used for data analysis and tabulation of results. The analysis procedures used were frequency tabulation and comparison of mean values of the quantitative strengths with respect to grades in respective age group. The independent sample t-test was used to calculate $p$-value to compare mean dynamometric strength across grade 4 and 5 .

\section{Results}

The mean age of the subjects was $23.11+4.70$ years. Table I, shows the frequency of participants in grade 4 and 5 in dominant and non-dominant extremities, respectively. A considerable number of population, 39.3 $\%$ in dominant and $39 \%$ in non-dominant extremity, was unable to hold to the maximal resistance of one of the testers.

The dynamometric measurements of muscle strength according to age groups in grade 4 and 5 is elaborated in table II \& III. The dominant wrist flexors were stronger than non-dominant. Both dominant and non-dominant wrist flexors showed an increase in mean strength across grade 5 with age. For dominant wrist flexors the strength measured for 18-19 years of age was $6.76 \pm 1.96 \mathrm{~kg}$ and the mean strength for age group of 3039 years was $8.27 \pm 1.37 \mathrm{~kg}$. Similarly, for non-dominant wrist flexors the strength measured for 18-19 years of age was $6.48 \pm 1.85 \mathrm{~kg}$ and the mean strength for age group of $30-39$ years was $7.78 \pm 1.40 \mathrm{~kg}$.

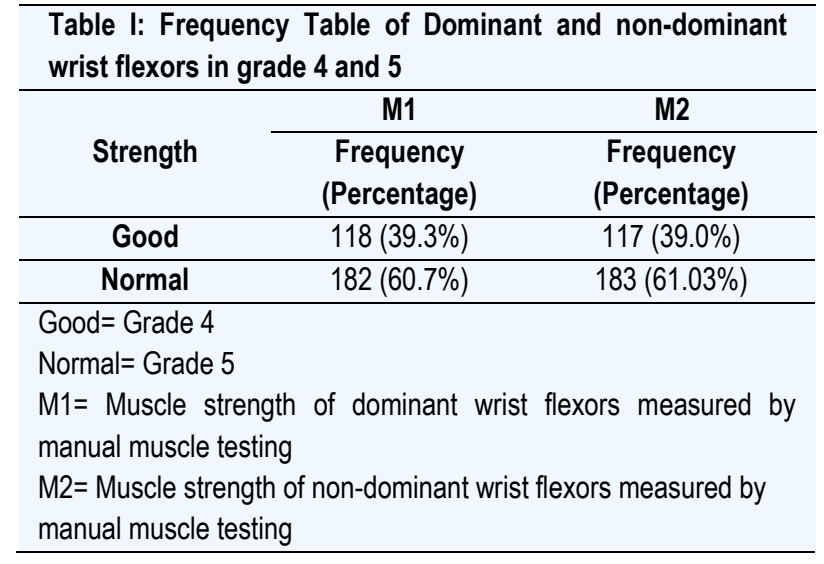

\section{Discussion}

The strength of wrist flexors of normal healthy females was evaluated and analyzed with the help of manual muscle testing and hand-held dynamometer. A considerable number of population showed strength in grade 4. Dominant wrist flexors of 118 participants were weaker that is they were found in grade 4 . This makes up 39.33 percent of observed population. Similarly, nondominant wrist flexors of 117 participants (that make up 39 percent of observed population) were found in grade 4 . This is a significant number. This highlights examination of cause of weaker strength in normal young population. Wrist flexion is an important component of fine motor movements and grip in hand. The lesser grip strength is considered as a marker of deteriorating health condition ${ }^{12}$, therefore grade 4 strength of wrist flexors in normal healthy population emphasizes the exploration of causes. It also points out the importance of devising a standardized procedure for deigning of reference values

\begin{tabular}{|c|c|c|c|c|c|c|c|c|}
\hline \multirow[b]{2}{*}{ Age $(Y)$} & \multirow[b]{2}{*}{ M1 } & \multicolumn{7}{|c|}{ D1kg } \\
\hline & & N & Mean (Kg.) & $\begin{array}{c}\text { Std. } \\
\text { Deviation }\end{array}$ & $\begin{array}{l}\text { Minimum } \\
(\mathrm{Kg})\end{array}$ & $\begin{array}{l}\text { Maximum } \\
(\mathrm{Kg})\end{array}$ & Range & P-value \\
\hline \multirow{2}{*}{ 18-19 } & Good & 29 & 6.44 & 1.65 & 3.63 & 10.09 & 6.46 & \multirow{2}{*}{0.35} \\
\hline & Normal & 37 & 6.76 & 1.96 & 3.63 & 10.66 & 7.03 & \\
\hline \multirow{2}{*}{$20-29$} & Good & 67 & 6.52 & 1.36 & 3.17 & 11.68 & 8.50 & \multirow{2}{*}{0.11} \\
\hline & Normal & 128 & 7.24 & 1.62 & 3.85 & 15.65 & 11.79 & \\
\hline \multirow{2}{*}{$30-39$} & Good & 22 & 6.82 & 1.34 & 3.40 & 8.84 & 5.44 & \multirow{2}{*}{0.91} \\
\hline & Normal & 17 & 8.27 & 1.37 & 5.44 & 11.34 & 5.90 & \\
\hline \multicolumn{9}{|c|}{ ength of dominant wrist flexors measur } \\
\hline \multicolumn{9}{|c|}{$\mathrm{D} 1=$ Muscle strength of dominant wrist flexors measured by Hand-Held Dynamometer expressed in $\mathrm{Kg}$. } \\
\hline \multicolumn{9}{|c|}{ Good= Grade 4} \\
\hline \multicolumn{9}{|c|}{ Normal=Grade 5} \\
\hline
\end{tabular}




\begin{tabular}{|c|c|c|c|c|c|c|c|c|}
\hline \multirow[b]{2}{*}{$\begin{array}{c}\text { Age } \\
(\mathrm{Y})\end{array}$} & \multirow[b]{2}{*}{ M2 } & \multicolumn{7}{|c|}{ D2kgs } \\
\hline & & $\mathbf{N}$ & $\begin{array}{c}\text { Mean } \\
(\mathrm{Kg})\end{array}$ & $\begin{array}{c}\text { Std. } \\
\text { Deviation }\end{array}$ & $\begin{array}{c}\text { Minimum } \\
(\mathrm{Kg})\end{array}$ & $\begin{array}{l}\text { Maximum } \\
(\mathrm{Kg})\end{array}$ & Range & $P$ - value \\
\hline \multirow{2}{*}{$18-19$} & Good & 32 & 6.21 & 1.95 & 3.40 & 11.68 & 8.28 & \multirow{2}{*}{0.76} \\
\hline & Normal & 34 & 6.48 & 1.85 & 3.29 & 11.45 & 8.16 & \\
\hline \multirow{2}{*}{$20-29$} & Good & 68 & 6.37 & 1.25 & 2.95 & 9.75 & 6.80 & \multirow{2}{*}{0.03} \\
\hline & Normal & 127 & 7.07 & 1.60 & 3.17 & 11.11 & 7.94 & \\
\hline \multirow{2}{*}{$30-39$} & Good & 17 & 6.90 & 0.88 & 5.33 & 8.39 & 3.06 & \multirow{2}{*}{0.06} \\
\hline & Normal & 22 & 7.78 & 1.40 & 5.44 & 10.43 & 4.99 & \\
\hline
\end{tabular}

M2= Muscle strength of non-dominant wrist flexors measured by manual muscle testing

D2= Muscle strength of non-dominant wrist flexors measured by Hand-Held Dynamometer expressed in $\mathrm{Kg}$.

Good $=$ Grade 4

Normal=Grade 5

for normal population requires a standardized approach

owing to weaker wrist flexors in apparent normal healthy population.

Van Harlinger et al. measured the reference value of wrist flexors by hand-held dynamometer. in this study it was found that the strength varies between $8.20 \pm 2.50 \mathrm{kgs}$ to $10.20 \pm 3.40 \mathrm{kgs}$ in dominant wrist flexors and $8.70 \pm 3.60 \mathrm{kgs}$ to $9.30 \pm 9.10 \mathrm{kgs}$ in non-dominant wrist flexors of young healthy females in the age groups of 20 39 years. The reduced strength in present study demands exploration of variables of strength measurement. (13) These variables include BMI, nutritional status and study of general health conditions of the population under study.

Various studies have discussed an overlap in strength in the context of subjectivity in grade 4 and 5 . Bohannon in his studies on knee extensors and grip strength has indicated that the strength variation in grade 4 and 5 causes reduced diagnostic worth of manual muscle testing with respect to dynamometric quantified strength.7, 14 The overlap in strength in present study indicates the dispersed range directing towards diversity entrenched in varying characteristics of population. This also shows the wide range of strength available in grade 4 and 5 which cannot be comprehended through subjective approach. This emphasizes importance of dynamometer to measure small strength differences which is important when muscle strength is used as a prognostic indicator.

The results of this study validates stronger dominant side as compared to non-dominant one as per quantitative measures which cannot be resolved with clarity on the basis of grades. It validates the results of previous reference studies which have also highlighted a stronger dominant side than non-dominant one. 15, 16
This study was conducted on Pakistani population. The overall strength of wrist flexors in population studied in this project was found less in comparison with already established reference values. This points out towards the need of compilation of normative databases in Asian races so that reference studies could be established. In future a study considering other muscle groups with different population in different age groups needed to be conducted. The age group of 35-39 years had less number of participants. This along with the possible variation in the strength of testers points out towards the limitations of the study. In this study the tester within same age group were selected to reduce bias. However further standardization of the process is needed.

\section{Conclusion}

This study concludes the variation in strength of wrist flexors of normal population with an overlap in quantitative strength across grade 4 and 5 . The dominant wrist flexors were stronger than non-dominant ones and a trend of increase in strength with age was followed.

\section{References}

1. Brumfield RH, Champoux JA. A biomechanical study of normal functional wrist motion. Clinical orthopaedics and related research. 1984(187):23-5.

2. Oatis CA. Kinesiology: The Mechanics and Pathomechanics of Human Movement: Lippincott Williams \& Wilkins; 2004.

3. Hislop HJ, Montgomery J. Daniels and Worthingham's Muscle Testing: Techniques of Manual Examination: Saunders Elsevier; 2007.

4. Florence JM, Pandya S, King WM, Robison JD, Baty J, Miller JP, et al. Intrarater reliability of manual muscle test (Medical Research Council scale) grades in Duchenne's muscular dystrophy. Physical therapy. 1992;72(2):115-22. 
5. Knepler C, Bohannon RW. Subjectivity of forces associated with manual-muscle test grades of 3+, 4-, and 4. Perceptual and motor skills. 1998;87(3_suppl):1123-8.

6. Dvir Z. Grade 4 in manual muscle testing: the problem with submaximal strength assessment. Clinical Rehabilitation. 1997;11(1):36-41.

7. Bohannon RW. Manual muscle testing: does it meet the standards of an adequate screening test? Clinical rehabilitation. 2005;19(6):662-7.

8. Sisto SA, Dyson-Hudson T. Dynamometry testing in spinal cord injury. Journal of rehabilitation research and development. 2007;44(1):123.

9. Andrews AW, Thomas MW, Bohannon RW. Normative values for isometric muscle force measurements obtained with hand-held dynamometers. Physical therapy. 1996;76(3):248-59.

10. Bohannon RW. Reference values for extremity muscle strength obtained by hand-held dynamometry from adults aged 20 to 79 years. Archives of physical medicine and rehabilitation. 1997;78(1):26-32.

11. Bäckman $E$, Johansson $V$, Häger $B$, Sjöblom $P$, Henriksson KJSjorm. Isometric muscle strength and muscular endurance in normal persons aged between 17 and 70 years. $1995 ; 27(2): 109-17$.

12. Siddique MA, Afzal MW, Ahmad A, Gilani SA, Saleemi MA. Quantitative Comparison of Handgrip Strength between Cardiac Patients and Age Matched Healthy Controls Using A Handheld Dynamometer. Khyber Medical University Journal. 2018;10(4):196-199.

13. Van Harlinger W, Blalock L, Merritt JL. Upper limb strength: study providing normative data for a clinical handheld dynamometer. PM\&R. 2015;7(2):135-40.

14. Bohannon RW. Grip strength measured by manual muscle testing lacks diagnostic accuracy. Isokinetics and Exercise Science. 2018(Preprint):1-4.

15. Bohannon RW, Peolsson A, Massy-Westropp N, Desrosiers J, Bear-Lehman J. Reference values for adult grip strength measured with a Jamar dynamometer: a descriptive meta-analysis. Physiotherapy. 2006;92(1):11-5.

16. Bohannon RW. Grip strength: a summary of studies comparing dominant and nondominant limb measurements. Perceptual and motor skills. 2003;96(3):728-30. 